\title{
Universal Energy Storage and Recovery System - A Novel Approach for Hydraulic Hybrid
}

\author{
M Erkkilä, F Bauer*, D Feld* \\ Hydac Oy, Tampere, Finland \\ *Hydac International GmbH, Sulzbach/Saar, Germany \\ E-mail: mikko.erkkila@hydac.fi, frank.bauer@hydac.com, daniel.feld@hydac.com
}

\begin{abstract}
The paper presents the basic principles of hybrid systems. It gives a rough approximation of factors that can affect the efficiency of a hybrid system. A Short comparison between hydraulic, mechanic and electric energy storing system is presented.

In a mobile working machine, there are mainly three possible sources for energy storage or recovery which are: energy of the combustion engine, when it is working on part load, braking energy of a vehicles kinetic energy and its hydraulic system.

A novel hydraulic system is introduced that is capable to store and recover energy from all energy sources of mobile working machine. The power peaks during the working cycles of the machine can be covered with energy stored in the hydraulic accumulator and so the size of the combustion engine can be reduced and dimensioned according to the average power. It also reduces the energy conversion losses. Simple and cost effective design makes it an attractive alternative for many applications.
\end{abstract}

Keywords: Hydraulic hybrid

\section{Introduction}

In mobile working machines the loading of the combustion engine is often not constant during the working cycle. Maximum power is in many cases needed only for short periods. Normally the combustion engine must be dimensioned according to the maximum peak power, which leads to oversized engines compared to the average power during the working cycle and to low efficiency, because the engine is running most of the time on part load. In the past it has not been a problem to increase the engine size, but the tightening of engine exhaust regulations like Euro/TIER and increased fuel cost will force the equipment manufacturer to search for new solutions.

During movements kinetic energy is charged in the vehicle and it is normally extinguished and wasted in the brakes, causing wear and thermal loading. More sophisticated transmissions, like Continuously Variable Transmissions (CVT) [1], hydrostatic, or electrical transmissions are able to transmit the braking energy back to the combustion engine. Unfortunately the braking capacity of the new low emission diesel engines is limited. In some applications, like in city busses or package delivery or garbage vehicles, in which the amount of braking energy is sufficient; energy recuperation systems have been tested and are in use.

By lifting of a load, potential energy is accumulated in the own mass of the lifting equipment. In a traditional hydraulic system, when the equipment is lowered, this energy is lost in the return notch of the control valve. Balancing systems can be used to compensate the dead weight. There are also proposals how the returning energy could be recovered.

In most of the studies only one of these three possible energy storing sources has been considered and the energy recuperation systems have been individually developed.

\section{Hybrid systems}

In the past years a lot of effort has been focused to the development of hybrid drives. Car industry has already taken hybrid solutions in mass production, in order to reduce fuel consumption.

In the branch of mobile working machines many studies and investigations have been carried out, regarding the possibility to use hybrid technology.

By side of energy saving one interesting chance for mobile working machines is the possibility to reduce the engine size.

Traditionally the engine has to be dimensioned according to the peak power of the machine. In many mobile machines there is a big difference between required average and peak power. Figure 1 show the so called Y-working cycle for a 
wheel loader, for filling a lorry $\mathrm{C}$ from a pile $\mathrm{B}$. And figure 2 the correspondent power demand from the engine during this cycle.

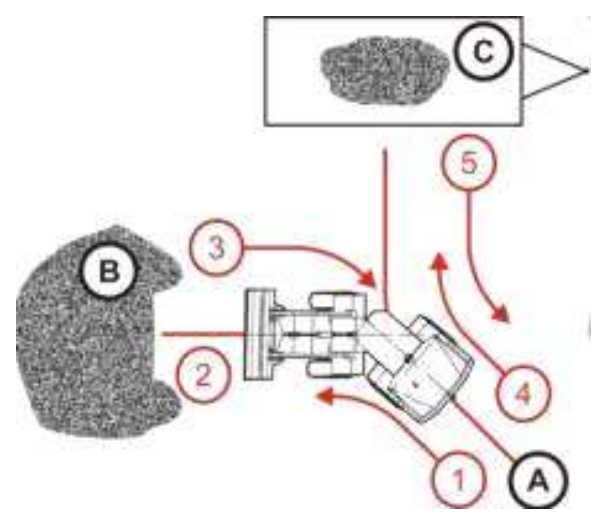

Figure 1: Y-working cycle of a wheel loader

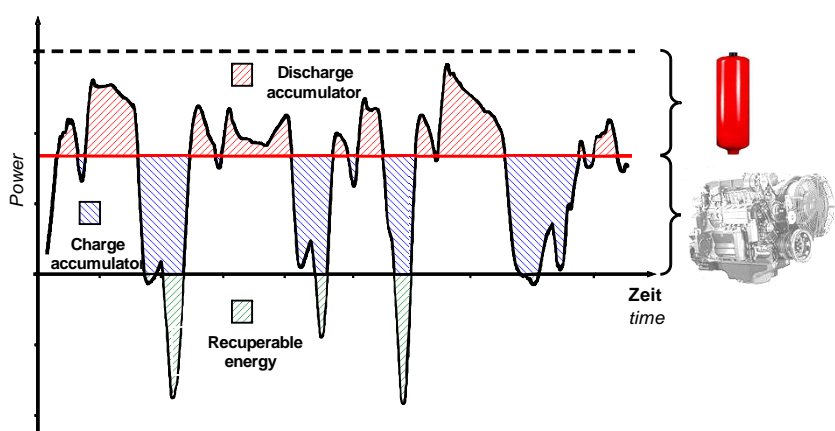

Figure 2: Power demand during the $Y$-working cycle [2]

From figure 2 we can see that the amount of recoverable energy is moderate. The main benefit for hybrid system in this kind of machines is to dimensioning the engine according to the average power and covers the peak power demand with the stored energy.

Hybrid drives can roughly be divided into two categories: parallel and serial hybrids

\subsection{Serial hybrid}

In the serial hybrid the total engine power is transformed to electrical or hydraulic power, from which the energy is stored and re-used. Figure 5 shows a typical hydraulic serial hybrid design.

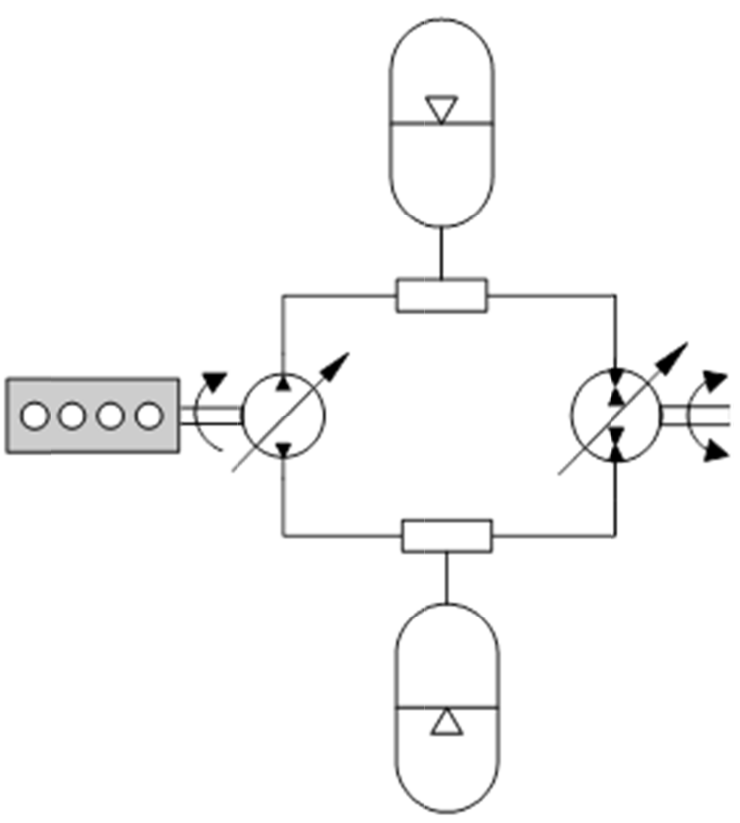

Figure 5: Serial hybrid system

In serial hybrid the engine is decoupled from the power consumers like powertrain or working hydraulics, which utilizes the possibility to optimize the engine control and efficiency only according to optimal energy production.

The disadvantage of a seriall hybrid is that the complete power in the main power train has to be transformed first to electrical or hydraulic power and then back to mechanical power. The main power line power loss is then:

$$
P_{l}=P_{e}\left(1-\eta_{\text {transfer } 1}\right)\left(1-\eta_{\text {transfer } 2}\right)
$$

,where:

$\mathrm{P}_{1}$ is power loss

$P_{e}$ is actual engine power

$\eta_{\text {transfer } 1}$, and $\eta_{\text {transfer } 2}$ are the power transform efficiencies.

\subsection{Parallel hybrid}

In parallel hybrid system the energy storing device is arranged in parallel to the main power line, and it has no influence to the basic function of it. Figure 6 shows the typical hydraulic parallel hybrid design. 


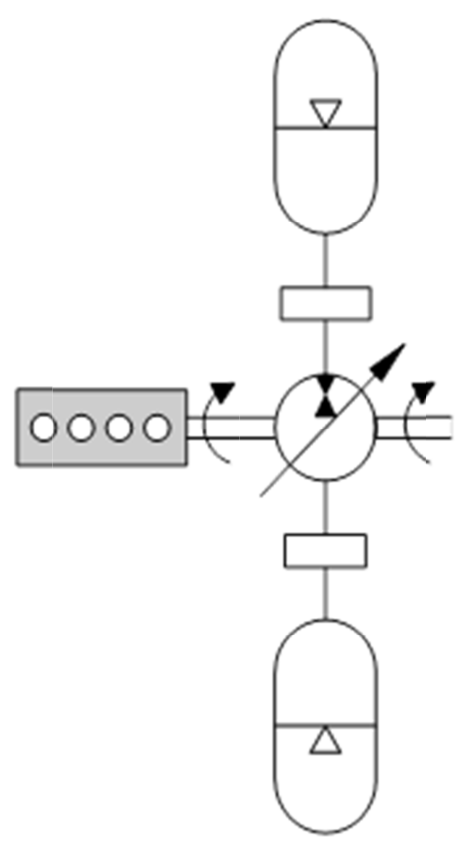

Figure 4: Parallel hybrid system

In parallel hybrid system the speed of the engine has to be controlled due to the requirements of the main power line. The parallel hybrid can only increase or decrease the engine torque.

If the accumulator is not charged or discharged, the main power line efficiency is only affected by the idle power loss of the energy storage device. The main power line power loss is then

$$
P_{l}=P_{i d l e}(p, n)
$$

, where

$\mathrm{P}_{1}$ is power loss.

$P_{\text {idle }}$ is power loss of the energy storing device, which normally depends on the pressures in high and low pressure accumulators and running speed of the engine.

When the accumulator is charged and discharged, the power loss can be defined as:

$p_{l}=Q\left(p_{\text {ha }}-p_{l a}\right)\left(1-\eta_{\text {transfer }}\right)+P_{\text {idle }(p, n)}$

where:

$\mathrm{Q}$ is the flow that is charged or discharger from or to the accumulator, and

$\mathrm{p}_{\mathrm{ha}}$ is the pressure in high pressure accumulator and

$\mathrm{p}_{\mathrm{la}}$ is the pressure in low pressure accumulator.

\section{Hydraulic accumulator as energy storage}

\subsection{Characteristics of a hydraulic accumulator compared with other energy storage devices}

Figure 3 shows the energy and power densities for different kind of energy storing devices.
The energy storing capacity of hydraulic accumulators is limited, but they are able to restore and discharge high power.

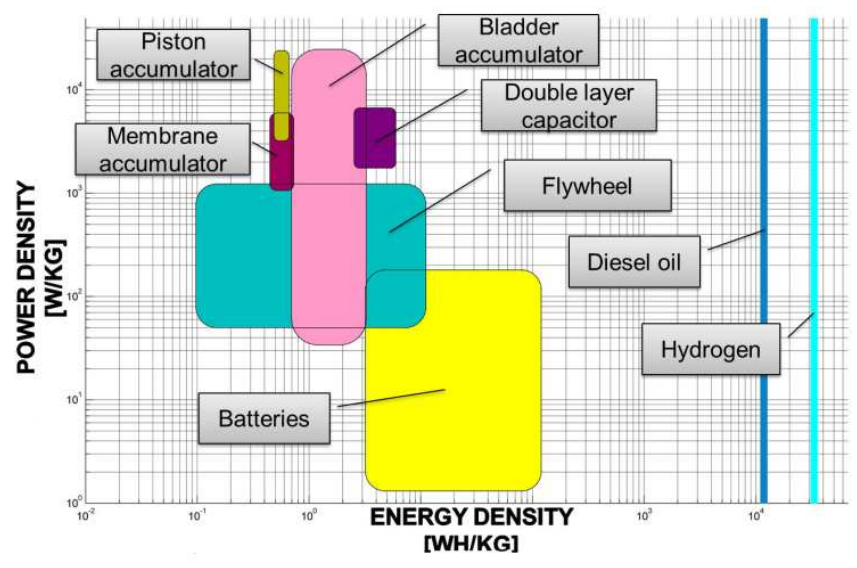

Figure 6: Energy and power densities of energy storage device [3]

Table 1 shows a comparison of the characters of electrical, mechanical and electrical power storing devices

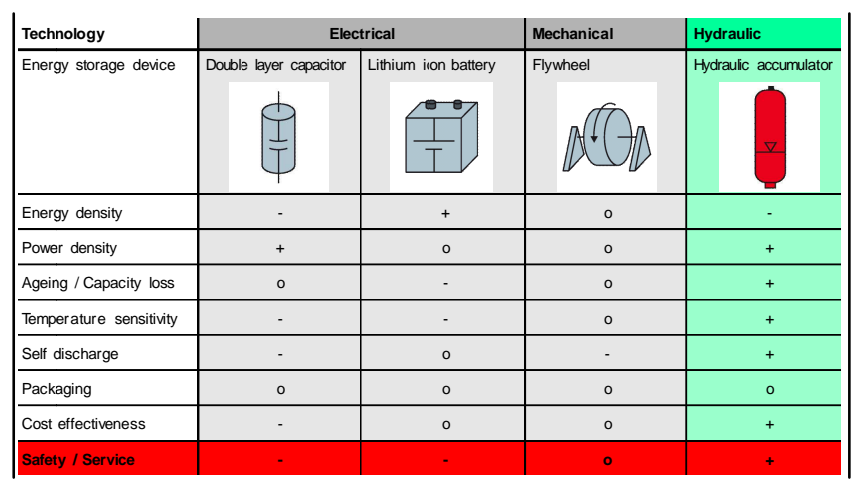

Table 1: Comparison of energy storing devices

In the past the main focus of hybrid drives has been concentrated to the development of electric hybrids due to the better efficiency of the electric components. A study made by Liebherr [4] shows that due to the high number of required energy transformations the total efficiency of electric hybrid systems can drop on the level of the hydraulic systems. See figure 7.

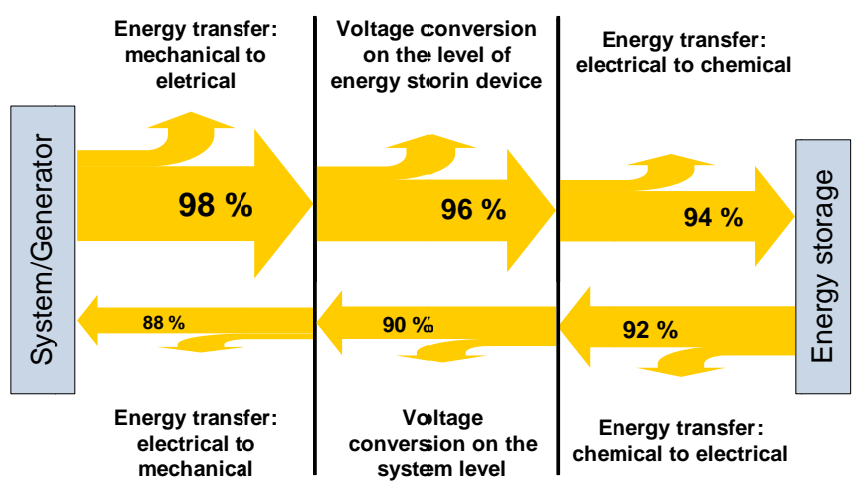

Figure 7: Power losses in electrical energy storage [4] 
On the other hand electric energy transfer can be dangerous in mobile machines which are working in rough environment. For example $60 \mathrm{~kW}$ means $600 \mathrm{~V}$ and $100 \mathrm{~A}$ or $100 \mathrm{~V}$ and $600 \mathrm{~A}$. Cable breaks or damaged cable isolations can cause far bigger problems than hydraulic hose breaks.

Hydraulic accumulators have been used several decades in mobile working machines. Security standards have been developed on a high level and security devices are well known and available.

In mobile working machines the required power is typically changing extremely during the working cycles and those are typically short. Due to the good power density hydraulic accumulators are suitable to compensate rapid power peaks.

\subsection{The energy storing capacity of a hydraulic accumulator}

The Energy capacity of a hydraulic accumulator for an ideal gas can be defined as [5]:

$E=\frac{p_{\min } V_{0}\left(\frac{p_{0}}{p_{\min }}\right)^{\frac{1}{K}}}{1-K}\left\lceil 1-\left(\frac{p_{\min }}{p_{\max }}\right)^{\frac{1-K}{K}}\right\rceil$

Where;

$\mathrm{E}$ is the energy capacity of the accumulator,

$\mathrm{V}_{0}$ is the volume of the accumulator,

$\mathrm{p}_{\min }$ is the minimum pressure

$\mathrm{p}_{\max }$ is the maximum pressure

$\mathrm{p}_{0}$ is the pre charge pressure of the accumulator

$\mathrm{K}$ is the adiabatic constant for nitrogen.

The figure 8 shows the energy capacity for a 10 Liter accumulator, with a maximum pressure of 350 bar as a function of $\mathrm{P}_{\min }$, when the pre charge pressure is $0.9 * \mathrm{P}_{\min }$.

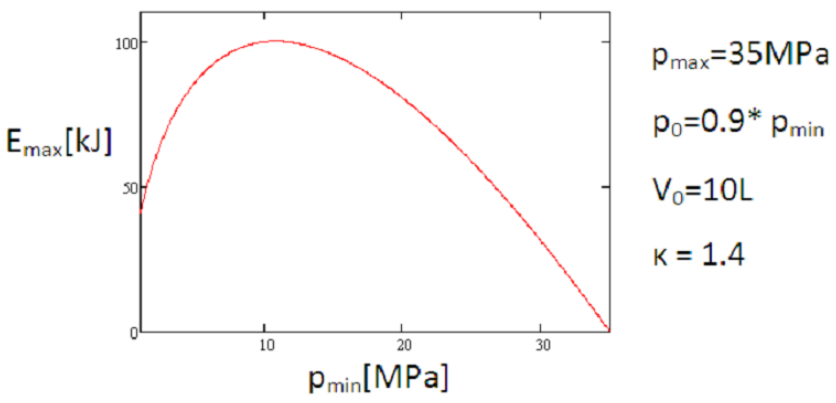

Figure 8: Theoretical energy storing capacity of a $10 \mathrm{~L}$ accumulator
In practice the accumulator has to operate on wide temperature range, which limits the theoretical power charging capacity. Hydac's ASP Accumulator Simulation Program is an excellent tool for dimensioning accumulators for hybrid solutions. It is based to real gas characteristics an thermo dynamical processes during loading and unloading.

In praxis a $50 \mathrm{~L}$ accumulator with operating pressure range maximum 330 bar and minimum 100 bar is able to store about $360 \mathrm{~kJ}$ energy. Figure 9 shows that with $360 \mathrm{~kJ}$ energy can be loaded, when a vehicle with weight of 10 ton is braked from a velocity of $36 \mathrm{~km} / \mathrm{h}$ to $19 \mathrm{~km} / \mathrm{h}$. With this stored energy it is possible to lift a load of 3,6 ton in a height of $10 \mathrm{~m}$.

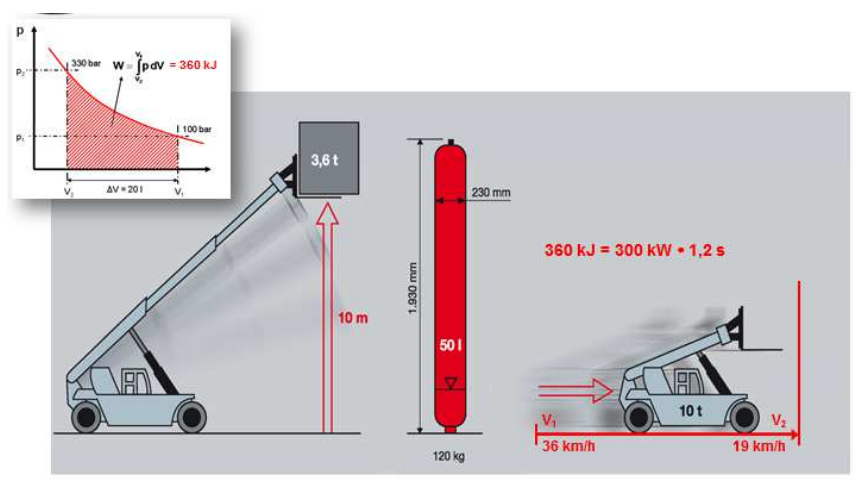

Figure 9: Practical energy capacity of a 50L accumulator

\section{Conventional hydraulic energy storing systems}

In the following some known hydraulic hybrid systems are shown.

\subsection{Adding an accumulator to a hydraulic system}

The easiest possibility to store energy is to add an accumulator to the hydraulic system as shown in figure 10 . 


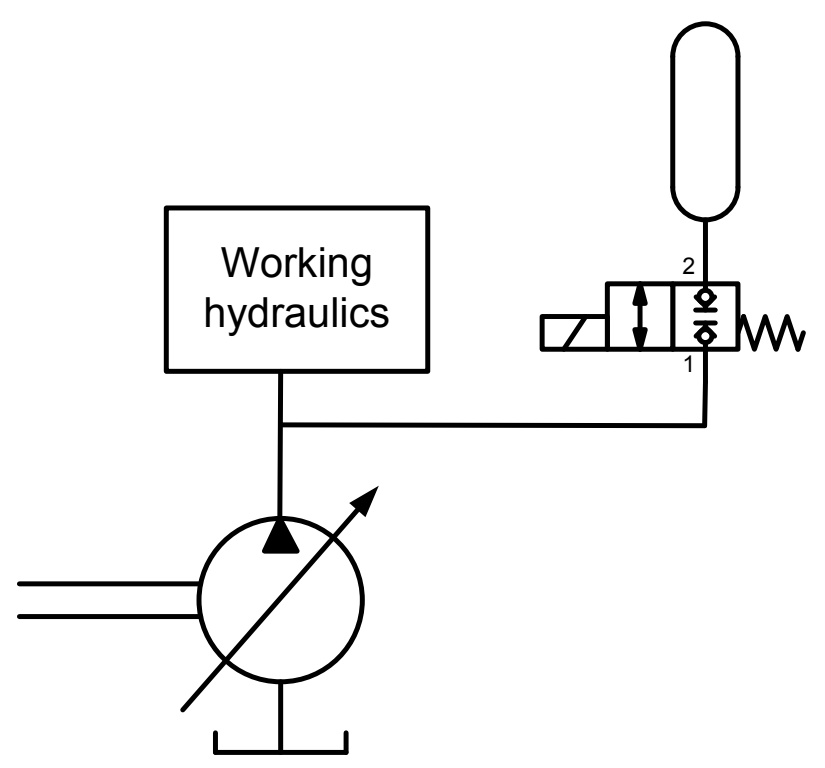

Figure 10: Simple energy storing system

This kind of system is used in a forestry machine application by the company HSM. Where energy is stored in the accumulator and used to accelerate the feeding rolls in a harvester head [6] see figure 11. According to HSM it was possible to reduce $20 \%$ fuel consumption with this system.

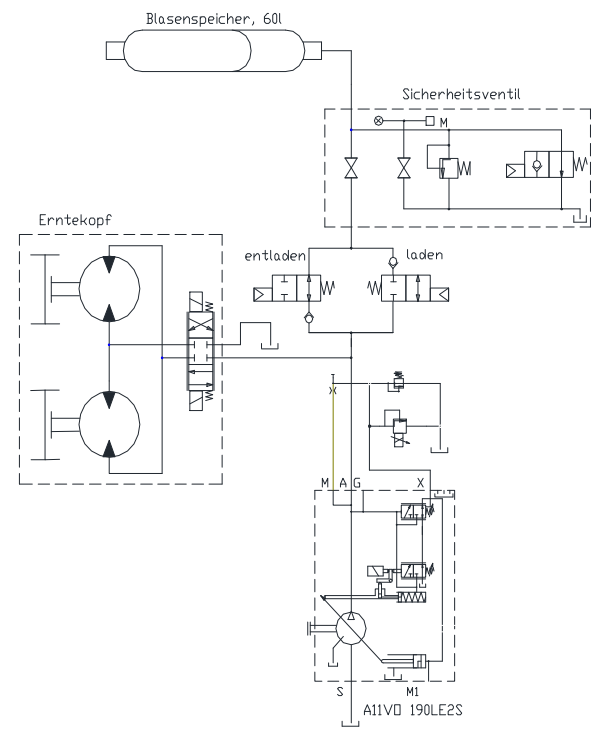

Figure 11: Serial hybrid system [6]

The main disadvantage for the general use of this kind of system is that the energy from the accumulator can only be used, when the pressure in the accumulator is higher than the load pressure, see figure 12 . The preloading and the minimum operating pressure of the accumulator can of course be chosen so that the accumulator pressure is always higher than the maximum load pressure, but also then the accumulator energy capacity is limited. Also the pressure difference between accumulator and system pressure is lost.

\section{Energy}

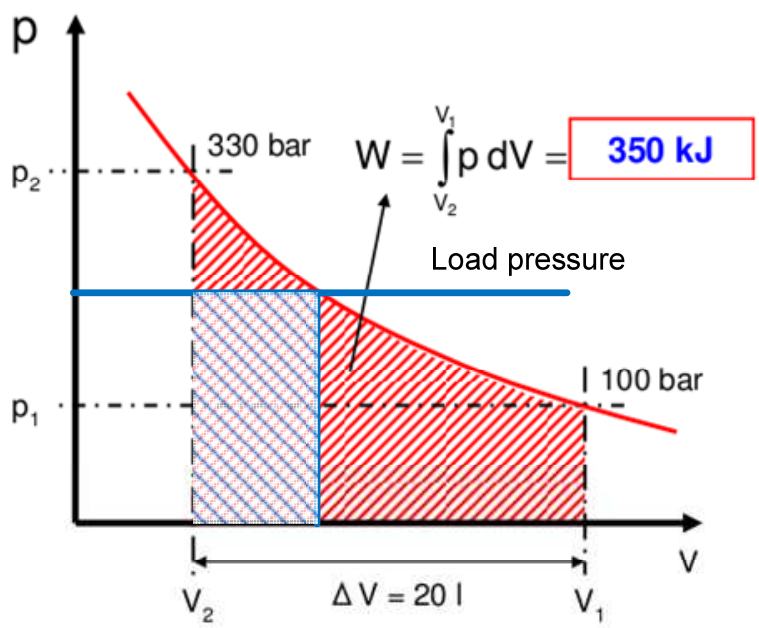

Figure 12: Usable energy capacity in a simple system, marked as blue

\subsection{Using an extra pump}

Figure 13 shows a hydraulic system, where an extra pump is used to charge and discharge the accumulator. The pump is mechanically driven from the engine and the transmission. It is then able to store braking energy and also energy from the engine, when the engine is not fully loaded.

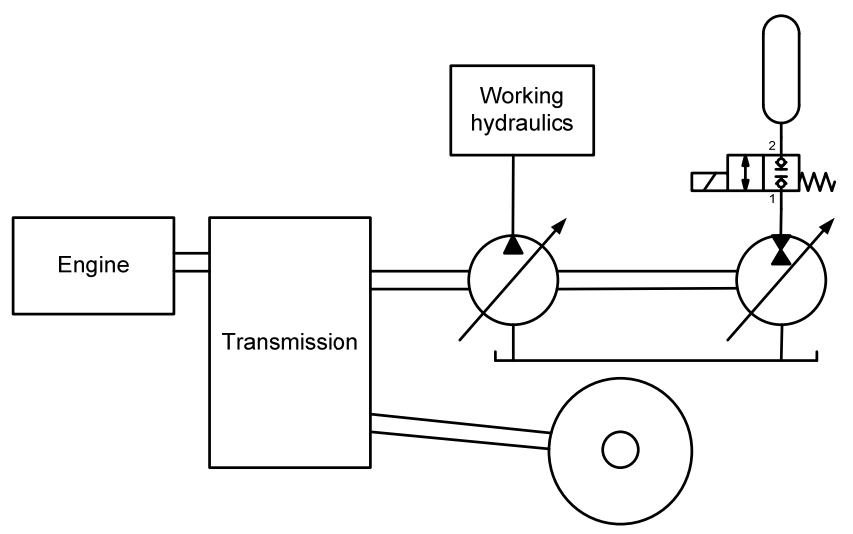

Figure 13: Additional pump/motor unit with accumulator as energy storing unit

This kind of energy storing system has been proposed by the Purdue university research team for the Multi-Actuator Hydraulic Hybrid Machine Systems [6] see figure 14. 


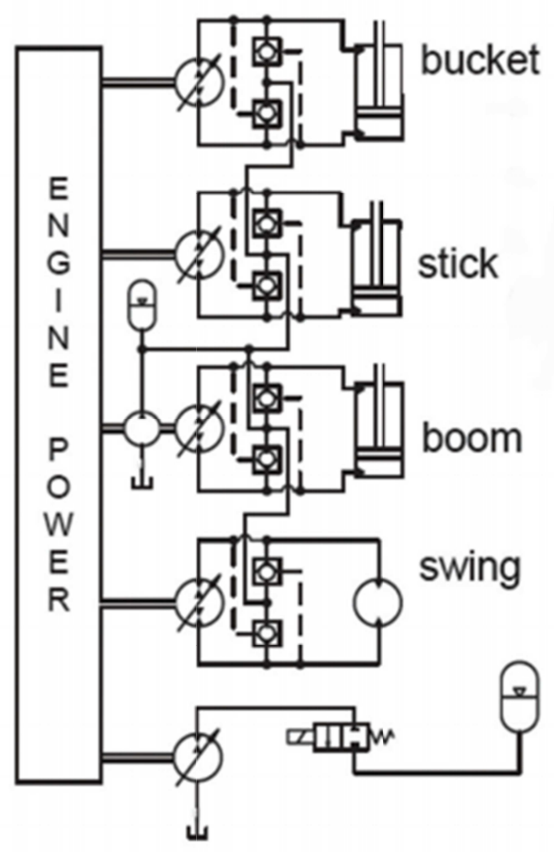

Figure 13: Additional pump/motor unit with accumulator as energy storing unit in Multi-Actuator Hydraulic Hybrid Machine System [7]

The main disadvantage of this system is that the energy from accumulator has to be first converted to mechanically energy, and then with the working hydraulic pump back to hydraulic energy. Due to the required energy conversions the energy losses are high and the overall efficiency is poor.

\section{A Novel Approach for Hydraulic Hybrid}

\subsection{System design}

In the new proposed system (see figure 15) a pump/motor unit that can be pressurized on both sides A and B is added to feed a hydraulic accumulator from the working hydraulic system. This kind of unit is normally used as pump in a closed loop power transmission system

The pump/motor unit can be driven as shown on the picture, direct or via through drive from the main engine or from gearbox that is connected to drive wheels.

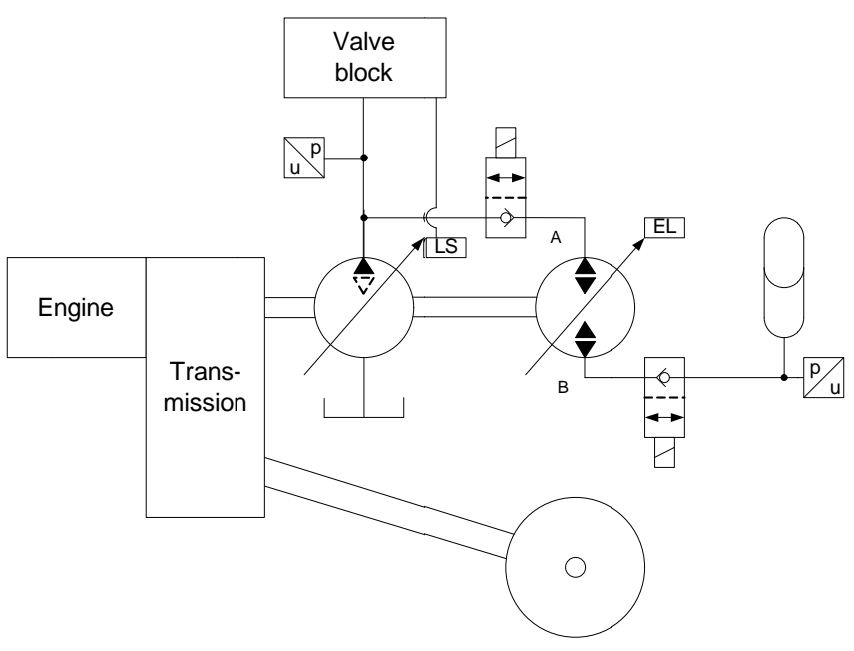

Figure 15: A new approach for hydraulic hybrid

\subsection{Function principle}

The hydraulic system can be designed as a normal Load Sensing system, where only a pump/motor unit and an accumulator are added.

The function of the pump/motor unit is to control the flow for charging the accumulator and controlling the flow from the accumulator to working hydraulics. It also works as pressure transformer between the accumulator and system pressure.

In the system there are also $2 / 2$-valves on the both sides of the pump/motor unit. With those valves it is possible disconnect the energy storing system from the working hydraulic system to avoid power loses, when the energy storing system is not activated during the operation of the machine. So the high pressure in accumulator or in working hydraulics is not increasing the hydromechanical or volumetric loses of the pump/motor unit.

The valves are working also as safety devices, when the A side valve is opened only accumulator loading is possible. When B side valve is opened the accumulator can be discharged.

\subsection{Energy storing}

The open loop Load Sensing pump keeps the A side of the pump/motor unit pressurized. When there is no flow consumption for the working hydraulics the Load Sensing pump is on Stand By pressure, normally on the level of about 20 bar. This is enough to assure the needed suction pressure and flow for the pump/motor unit.

If there is a parallel need for working hydraulics the Load Sensing pump pressure is controlled according to the needed load pressure. In this case the pump/motor unit works as a pressure transformer between the Load Sensing pump and accumulator pressure. The pump/motor unit can use the rest of the available flow capacity of the main pump to charge the accumulator. 
The amount of the stored energy is controlled with the displacement control of the pump/motor unit.

\subsubsection{Energy storing from the engine}

When during the working cycles of the machine, there are periods, when the engine power is not fully used, the remaining energy can be stored to the accumulator.

The amount of stored power can be controlled with the displacement control of the pump/motor unit.

\subsubsection{Braking energy}

Modern driveline designs, like hydrostatic transmissions, or CVT are able to transmit the braking energy from the drive wheels back to the diesel engine. The braking capacity of modern diesel engines is limited, and the braking energy cannot be stored.

With the proposed system the braking energy from the driveline can be stored to the accumulator.

The braking force and power can be controlled by the displacement control of the pump/motor unit.

One big advantage of the braking energy storing system is that the wear and the heating of the vehicle brakes can be reduced.

\subsubsection{Energy storing from the hydraulic system}

If the hydraulic system is capable to return pressurized flow from the working hydraulic system, the returning oil flow from the main valve block can be restored to the accumulator.

\subsection{Re-use of stored energy}

Stored energy can be used for the working hydraulics.

The pressure level of the hydraulic system is controller with the Load Sensing pressure. With the displacement control of the pump/motor unit the amount of oil that is taken from the accumulator or from the LS-pump can be controlled.

The flow from the accumulator is used via the pump/motor unit to the main hydraulic system.

The motor/pump unit transforms the pressure between system and accumulator pressure. When the pressure in the system is higher, than that in the accumulator the closed loop unit works as pump and takes the needed extra power from the engine. When the system pressure is lower, than the one in the accumulator the closed loop unit works as motor and releases energy to the engine, driveline or auxiliary devices.

The whole accumulator capacity can then be utilized.
Figure 16 shows the usability of the stored energy of a 50 liter accumulator, with a total energy storage capacity of 350 $\mathrm{kJ}$.

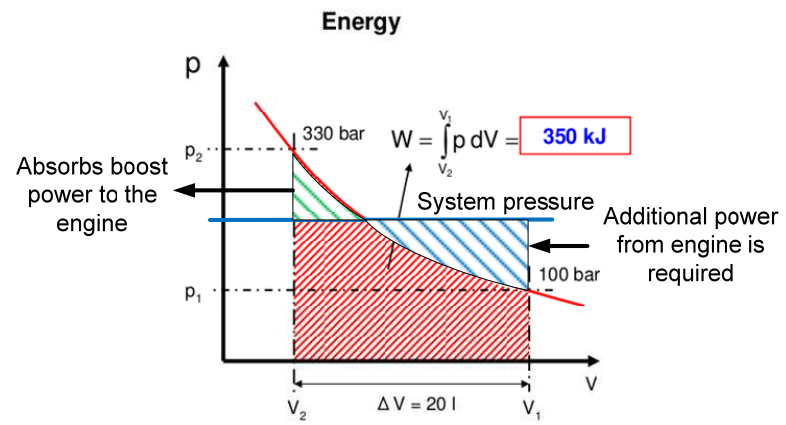

Figure 16: Energy usability in the proposed hydraulic hybrid system

If the LS-pump is a unit that can work as a motor (mooring unit) the stored energy can be used for boosting the drive line or for auxiliary units.

\subsection{Power losses and efficiency}

The power losses of the proposed system can be defined as follows:

$P_{l}=P_{\text {idle }(p, n)}+Q\left(p_{s}-p_{a}\right)$,

where:

$\mathrm{P}_{1}$ is power loss

$\mathrm{P}_{\text {idle(p,n) }}$ is constant power loss, depending of the pressure and rotation speed.

$\mathrm{Q}$ is flow to (or from) the accumulator,

$\mathrm{p}_{\mathrm{s}}$ is system pressure and

$\mathrm{p}_{\mathrm{a}}$ is accumulator pressure.

The main power loss:

$Q\left(p_{s}-p_{a}\right)$

depends only on the flow, which is stored or taken out of the accumulator and the pressure difference between accumulator and system pressure.

This offers a remarkable advantage compared with traditional serial or parallel hybrid systems.

\subsection{Benefits}

The size of the engine can be reduced, because it only needs to deliver the average power, not the max peak power during the working cycle. 
The hydraulic system can be designed as a normal Load Sensing system, where the main pump pressure is controlled by the LS pressure.

The flow from the accumulator is used via the pump/motor unit to the hydraulic system. The LS pump size can then be chosen smaller or the working speed of the machine can be increased.

The motor/pump unit controls the flow rate that is stored or taken out from the accumulator.

The main advantages of the system are listed as follows:

- Simple system design

- Universally usable for restoring energy

- No pressure losses, as in a valve controlled system

- Min. energy transformation loses

- Flow from the accumulator can be directly used for the working hydraulics:

- Smaller main pump can be used

- Reduced tank flow: smaller tank can be used

- The accumulator energy storing capacity can be used on a wide pressure variation range and the full energy storage capacity of the accumulator can be used.

\section{Outlook and conclusions}

Hydraulic hybrid is a good alternative to improve total efficiency and to reduce the size of the engine in a mobile working machine.

In the design of hybrid systems, it is important to reduce energy transforming losses to the minimum.

The proposed new hydraulic hybrid system can fulfill all requirements regarding energy storing from different restorable sources. It is also capable to use the full accumulator capacity. And can minimize energy transformation loses.

The novel system design has only been shown on a principle level. For real system some kind of power management system is needed to control the charging and the discharging functions.

\section{References}

[1] Erkkilä M, Model-Based Design of Power-Split Drivelines, Dissertation, September 2009 Tampere Finland

[2] Bauer, F., Feld, D. Warum hydraulische Hybridsysteme? Het Hydrauliek Symposium, Delft, $87-104,2010$

[3] Thiebes, P., Geimer, M., Energy storage devices for industrial vehicles with hybrid drive trainsQuelle: 1. VDI Fachkonferenz: "Getriebe in mobilen Arbeitsmaschinen" 07./08. Juni 2011 in Friedrichshafen

[4] Boehm, D. , Holländer, C., Landman, T., HybridAntriebe bei Raubenbaggern - Konzepte und Lösungen, Hybridantriebe für Arbeitsmaschinen, Karlsruher Schriftenreihe Fahrzeugsystemtechnik, 7:117-124, 2011.

[5] Sahlman, M., Valve controlled multi-chamber cylinder, Master's theses Tampere University of Technology, 2012

[6] Prinz zu Hohenlohe, F., Phlegmatisierung als Tugend in der Mobilhydraulik - Das Energiespeichersystem des Kranvollernters HSM 405H2, Hybridantriebe für mobile Arbeitsmaschinen, Karlsruher Schriftenreiche Fahrzeugsystemtechnik, 7:151-163, 2011

[7] http://www.ccefp.org/sites/all/files/documents/Info 1A.2 MultiActuator Hybrid.pdf Downloaded 8.4.2013 